\title{
Chemical modification allows phallotoxins and amatoxins to be used as tools in cell biology
}

\author{
Jan Anderl ${ }^{1}$, Hartmut Echner ${ }^{2}$ and Heinz Faulstich ${ }^{* 3}$
}

\section{Full Research Paper}

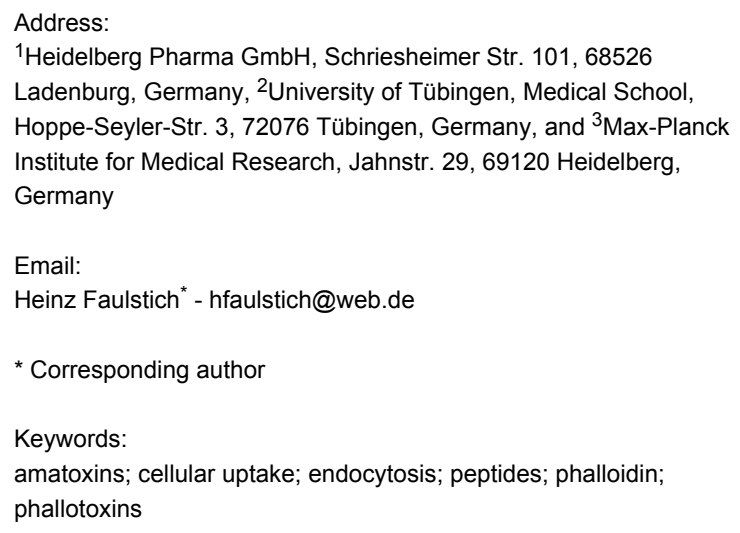

\begin{abstract}
Phallotoxins inhibit the dynamics of microfilaments in cells and lead to apoptosis. Due to poor cellular uptake these effects cannot be studied in live cells, even at millimolar toxin concentrations, nor can phalloidin be used for the elimination of tumor cells. Uptake is greatly enhanced by conjugation of phallotoxins to either lipophilic or polycationic moieties, such as oleic acid, polylysine, or Tat-peptide. These conjugates were lethally toxic for cells, e.g., mouse fibroblasts or Jurkat leukemia cells, in the micromolar range. Uptake into cells starts with the attachment of the toxin conjugates to the plasma membrane, followed by endocytosis and, in most cases, cleavage of the toxin from the carrier. Interestingly, the internalization rate of phalloidin into cells was also significantly increased by the fluorescent moiety tetramethylrhodaminyl, as well as by high molecular weight methoxy-polyethyleneglycol, two compounds unknown so far for their uptake-mediating activity. Conjugation to carriers as investigated in this work will allow the use of phallotoxins in experimental cell biology and possibly in tumor therapy. The findings obtained with phallotoxins could be applied also to the family of amatoxins, where $\alpha$-amanitin, for example, when conjugated to oleic acid was more than 100 -fold more toxic for cells than the native toxin. This suggests the possibility of a more general use of the moieties examined here to enhance the uptake of hydrophilic peptides, or drugs, into live cells.
\end{abstract}

\section{Introduction}

Phallotoxins and amatoxins, the two families of toxic cyclopeptides produced by the green death cap Amanita phalloides, have been the subject of intense biochemical research for decades [1]. Although produced by the same mushroom and of similar structure, the two peptide families have totally different cellular targets. Phallotoxins, such as phalloidin, bind to polymeric actin, thus stabilizing microfilaments and decreasing the amount of monomeric actin in equilibrium with the filaments. This 
interaction is in the nanomolar range and highly specific: no other targets for phalloidin in the cell are known. Amatoxins, such as the main toxin $\alpha$-amanitin, bind to RNA-polymerases II of eukaryotic cells, thus inhibiting the transcription process at nanomolar concentrations. Also this interaction is specific, since RNA-polymerases I are not inhibited at all, whereas RNA-polymerases III are inhibited at amanitin concentrations ca. 1000 times higher than for RNA-polymerases II [2,3]. The fact that both the cytoskeleton and the eukaryotic transcription machine are complex structures and still under investigation, may explain the continuing interest in these two kinds of specific inhibitors.

Phalloidin has been used to study actin dynamics in vitro [1], and in microscopic studies after microinjection into single cells [4]. Beside such experiments phalloidin conjugated to fluorescent moieties is widely used for visualizing filamentous actin in fixed cells $[5,6]$. In all these applications, cell-free systems were used, allowing direct access of phallodin to its target. Similarly, $\alpha$-amanitin was mainly used with isolated nuclei or the solubilized enzyme, as recently reported for stabilizing yeast RNApolymerase II in an X-ray analysis [7].

For both phallotoxins and amatoxins, experience with live cells is limited by the fact that the peptides cross the plasma membrane barrier only very slowly. Poor uptake rates of phallotoxins and amatoxins have been observed for most mammalian cells. Mammalian hepatocytes are an exception: they display transporting proteins on their sinusoidal surface (such as OATP1B1 and OATP1B3 of human hepatocytes [8-10]), which internalize phallotoxins and amatoxins. It is through the presence of the transporting protein OATP1B3 on human hepatocytes, for example, that amatoxins are feared as liver toxins causing the majority of fatal human mushroom poisonings worldwide.

The aim of this study was to explore known lipophilic and polycationic internalization-mediating moieties for their applicability with phallotoxins and amatoxins, and to find novel internalization-mediating moieties and investigate the potential of their conjugates with toxins as specific inhibitors in cultured cells The internalization-mediating moieties used in this study were either lipophilic in nature (such as oleic acid), or multicationic (such as polylysine and octarginine): two features applying also to so-called membrane-transducing peptides $[11,12]$.

\section{Results}

\section{Preparation of phallotoxin derivatives}

Attachment sites in phalloidin (Figure 1) for conjugation with uptake-mediating moieties were chosen based on our knowledge of structure-activity relationships in phalloidin [1]: As the side chains in the small heterodet peptide ring are known to be involved in actin binding they were not used for derivatization. In the larger peptide ring, on the other hand, the dihydroxylated leucine moiety is juxtaposed to the actin binding site and thus appeared as most promising for derivatization. Accordingly, all residues investigated in this study were attached to the $\mathrm{C} \delta$-atom of the dihydroxylated leucine moiety, either as esters or amides (Table 1). Large residues, which might disturb the interaction of a phalloidin derivative with actin through steric hindrance, were coupled via disulfide-containing linkers, which would be reduced inside the cell so as to release a defined thiol derivative of phalloidin (Table 1).

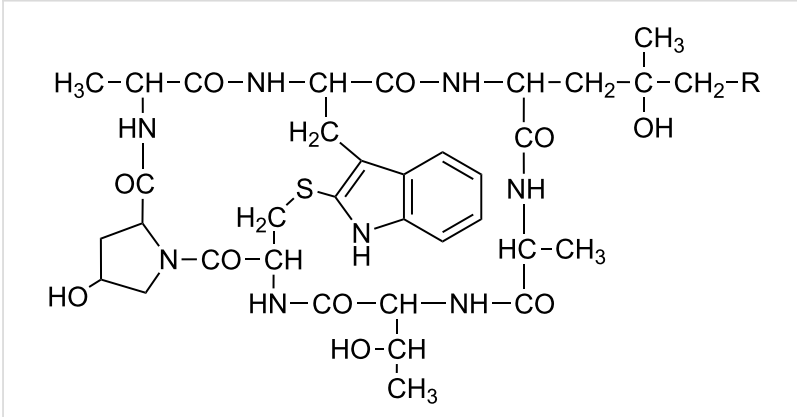

Figure 1: Chemical structure of phalloidin with the attachment site $(R)$ used for conjugation to uptake-mediating moieties.

\section{Actin binding}

All phalloidin derivatives were tested for their affinity to muscle actin ( $\alpha$-actin), which is used as a model for $\beta$-actin present in nonmuscle cells. This parameter was important, since cytotoxicity depends not only on membrane permeability but also on actin affinity. Moreover, this parameter will hint on whether phalloidin was cleaved from its carrier inside the cell, in cases where low actin affinity of a phalloidin derivative was combined with high cytotoxicity. Relative affinity values of the phalloidin derivatives to muscle actin are shown in Table 1.

\section{Growth inhibition of mouse fibroblasts}

By using the MTT cell proliferation assay, each phalloidin conjugate was examined for its capacity to inhibit the growth of mouse fibroblasts in vitro after $72 \mathrm{~h}$ incubation time (Table 1). Phalloidin displayed no antiproliferative activity up to a concentration of $10^{-3} \mathrm{M}$ in the culture medium. In contrast, the most lipophilic ester derivative, phalloidin oleate (1e), showed an $\mathrm{IC}_{50}$ value of proliferation inhibition of $2.5 \times 10^{-6} \mathrm{M}$, and was thus ca. 1000 times more active than phalloidin. Other esters (1a-1d) exhibited increasing cytotoxic activities with increasing hydrophobicity (Figure 2). In order to examine a possible relationship between cytotoxicity and hydrophobicity we determined the octanol/water equilibrium distribution coefficient of the ester derivatives $\left(\log P_{\mathrm{ow}}\right.$ values) and found a linear rela- 
Table 1: Structures of phalloidin derivatives, their relative affinity values for $\alpha$-actin as compared to phalloidin and their $\mathrm{IC}_{50}$ values of cell growth inhibition after incubation for $72 \mathrm{~h}$ as determined by MTT cell proliferation assay (n.a.: not assayed).

$\mathrm{R}$
Name/designation

$\begin{array}{ccc}\text { Relative } & \mathrm{IC}_{50} \text { values } & \mathrm{IC}_{50} \text { values } \\ \text { affinity to } & \mathrm{NIH} 3 \mathrm{~T} 3 & \text { Jurkat cells } \\ \text { a-actin }[\%] & \text { fibroblasts } & {[\mu \mathrm{M}]}\end{array}$

\begin{tabular}{|c|c|}
\hline 1 & $\mathrm{OH}$ \\
\hline $1 \mathrm{a}$ & $\mathrm{OCOC}_{6} \mathrm{H}_{5}$ \\
\hline $1 b$ & $\mathrm{OCOC}_{6} \mathrm{H}_{4} \mathrm{O}-\mathrm{OH}$ \\
\hline 1c & $\mathrm{OCOC}_{7} \mathrm{H}_{15}$ \\
\hline $1 d$ & $\mathrm{OCOC}_{13} \mathrm{H}_{27}$ \\
\hline $1 e$ & $\mathrm{OCO}\left(\mathrm{CH}_{2}\right)_{7} \mathrm{CHCH}\left(\mathrm{CH}_{2}\right)_{7} \mathrm{CH}_{3}$ \\
\hline 2 & $\mathrm{NH}_{2}$ \\
\hline $2 a$ & $\mathrm{NHCOC}_{6} \mathrm{H}_{5}$ \\
\hline $2 b$ & $\mathrm{NHCO}\left(\mathrm{CH}_{2}\right)_{7} \mathrm{CHCH}\left(\mathrm{CH}_{2}\right)_{7} \mathrm{CH}_{3}$ \\
\hline 2c & $\begin{array}{l}\mathrm{NHCO}\left(\mathrm{CH}_{2}\right)_{2} \mathrm{SS}(\mathrm{Ac}) \text { CysGlyTyrGly- } \\
-\mathrm{Arg}(\mathrm{Lys})_{2}(\mathrm{Arg})_{2} \mathrm{Glu}(\mathrm{Arg})_{3} \mathrm{OH}\end{array}$ \\
\hline $2 d$ & $\mathrm{NHCO}\left(\mathrm{CH}_{2}\right)_{2} \mathrm{SS}(\mathrm{Ac})$ CysGly $(\mathrm{Arg})_{8} \mathrm{OH}$ \\
\hline $2 e$ & $\mathrm{NHCO}\left(\mathrm{CH}_{2}\right)_{6} \mathrm{CONH}(\text { Lys })_{210}$ \\
\hline $2 f$ & $\mathrm{NHCO}\left(\mathrm{CH}_{2}\right)_{2} \mathrm{SS}\left(\mathrm{CH}_{2}\right)_{2} \mathrm{CONH}(\text { Lys })_{210}$ \\
\hline $2 \mathrm{~g}$ & $\mathrm{NH}\left(\mathrm{CH}_{2}\right)_{2} \mathrm{SS}\left(\mathrm{CH}_{2}\right)_{2} \mathrm{CONH}(\mathrm{PEG})_{800}$ \\
\hline $2 \mathrm{~h}$ & $\mathrm{NH}\left(\mathrm{CH}_{2}\right)_{2} \mathrm{SS}\left(\mathrm{CH}_{2}\right)_{2} \mathrm{CONH}(\mathrm{PEG})_{5.200}$ \\
\hline $2 \mathbf{i}$ & $\mathrm{NH}\left(\mathrm{CH}_{2}\right)_{2} \mathrm{SS}\left(\mathrm{CH}_{2}\right)_{2} \mathrm{CONH}(\mathrm{PEG})_{23.000}$ \\
\hline $\begin{array}{l}2 f \\
+ \text { DTT }\end{array}$ & $\mathrm{NH}\left(\mathrm{CH}_{2}\right)_{2} \mathrm{SH}$ \\
\hline
\end{tabular}

3 for structure see Figure $6 a$

phalloidin

(1)-benzoate

(1)-salicylate

(1)-octanoate

(1)-myristate

(1)-oleate

aminophalloidin

$N$-benzoyl-(2)

$\mathrm{N}$-oleoyl-(2)

(2)-Tat-peptide

(2)-octarginine

(2)-poly-(L)-lysine 28,000

(2)-poly-(D)-lysine 28,000

(2)-(SS) poly-(L)-lysine 28,000

(2)-(SS) poly-(D)-lysine 28,000

(2)-(SS) $P E G_{800}$

(2)-(SS) $P E G_{5,200}$

(2)-(SS) $P E G_{23,000}$

$\mathrm{N}$-(2-mercaptoethyl)-(2)-SH

dithiolanoaminophalloidin TRITC labeled ca. 1,000

92

364

44

11

3

ca. 1,000

693

883

4

11

5

54

3

4

167

77

10

n.a.

11 ca. 1,000

94

96

37

9

2

ca. 1,000

599

630

3

7

4

37

2

2

98

50

10

n.a.

25

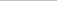




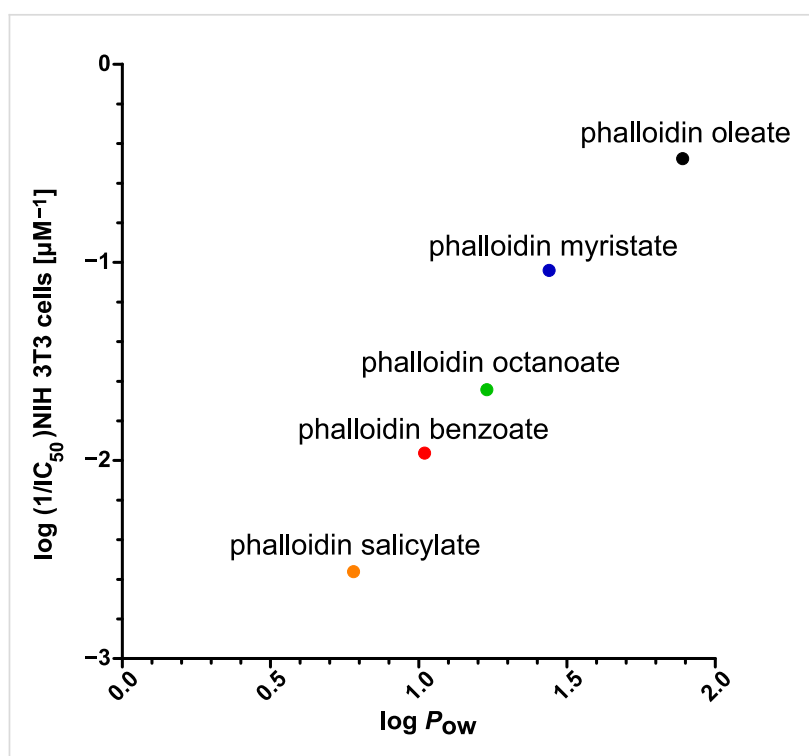

Figure 3: $n$-Octanol/water distribution coefficients $\left(\log P_{\text {ow }}\right)$ of the hydrophobic phalloidin derivatives of Figure 2 plotted versus cell toxicity $\left(\log \left(1 / / C_{50}\right)\right.$ in NIH 3 T3 mouse fibroblasts.
Polycationic derivatives of phalloidin, such as the polylysine conjugates, were highly toxic for mouse fibroblasts, and their antiproliferative activity was comparable to the most lipophilic derivative, phalloidin oleate (Figure 4a). Their toxicity was found to be dependent on the configuration of the polymer, since phalloidin bound to D-configurated polylysine was about 10 times less toxic than when bound to poly-(L)-lysine. This suggests that the release of a toxic phalloidin species inside the cell includes the enzymatic breakdown of the carrier. In agreement with this we found no difference between the L-configurated and the D-configurated carrier when the linker contained a disulfide bridge, arguing for the presence of a disulfidereducing compartment inside the cells.

Likewise, high cytotoxicity was found for the octarginine conjugate (Figure 4a). From the fact that the cytotoxic activities of the polylysine derivative (ca. 150 residues) and the oligoarginine derivative ( 8 residues) are comparable, we argue that arginine residues are more effective in mediating internalization of phalloidin than are lysine residues.
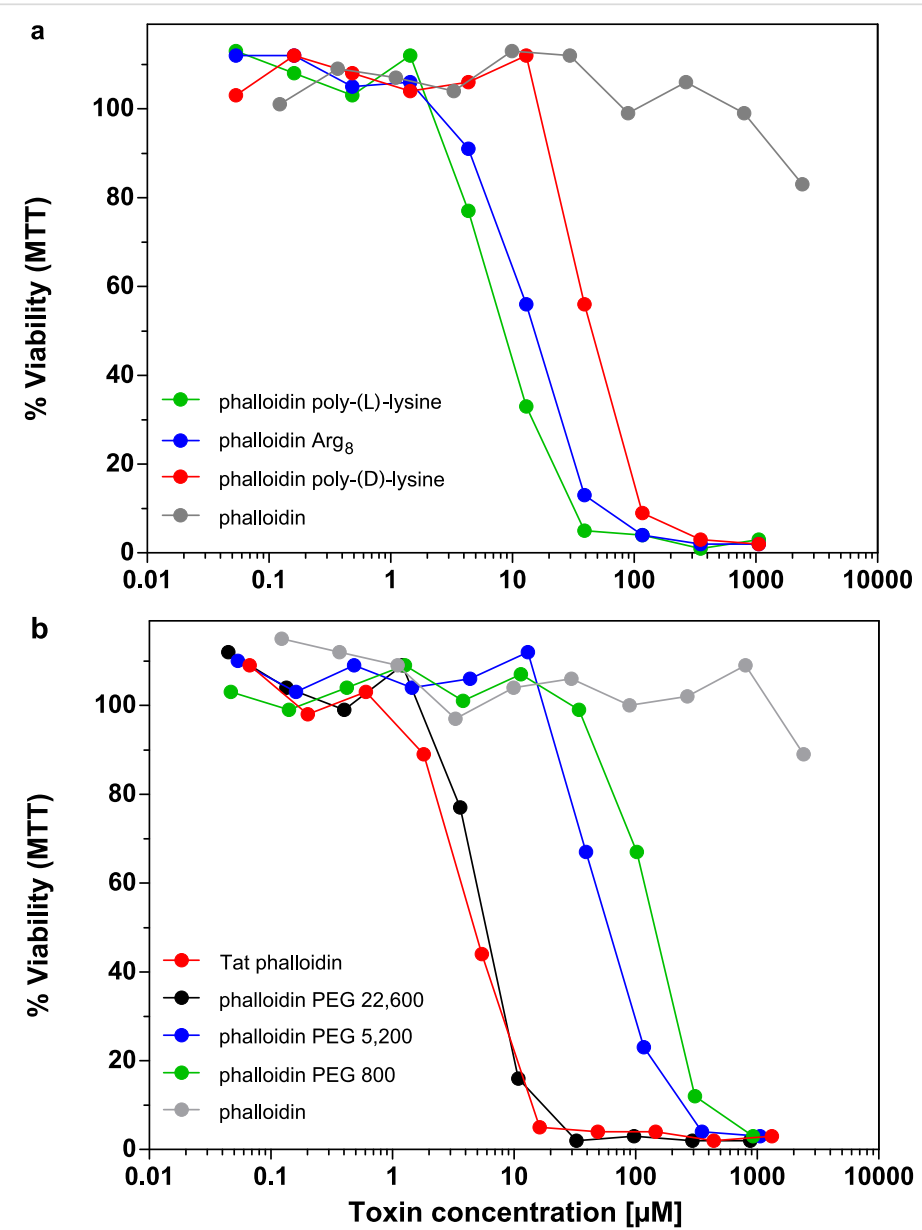

Figure 4: (a) and (b): NIH 3T3 mouse fibroblasts were incubated with various concentrations of phalloidin and phalloidin derivatives. Cell viability was determined after $72 \mathrm{~h}$ incubation time by MTT assay. 
For phalloidin bound to methoxy-polyethylene-glycol we found that cytotoxicity strictly depended on the molecular weight of the polymer chain (Figure 4b). Most active was the conjugate with the longest chain $\left(M_{\mathrm{r}}=22,600\right)$. Cytotoxicity fell strikingly when the polymer chain was shortened (Table 1).

Coupling to Tat-peptide was also very effective in enhancing the cytotoxicity of phalloidin (Figure 4b), while the phalloidin conjugate with the Kaposi protein fragment (likewise claimed to enhance membrane permeability) was much less effective (data not shown).

Beside mouse fibroblasts, we investigated the phalloidin derivatives in several human leukemia and lymphoma cell lines, in order to find possible specificities for one or the other kind of tumor cell. However, Jurkat cells (Table 1) and all other cell lines tested (K562 cells, HL-60 cells, and Daudi cells) showed sensitivities comparable to mouse fibroblasts (see Supporting Information File 1).

\section{Uptake kinetics}

Since the toxic effects of phalloidin develop slowly, growth inhibition was measured only after $72 \mathrm{~h}$. During this period several partial processes must occur such as binding to the plasma membrane, internalization, processing and toxin release, etc., which cannot be distinguished. However, replacement of the toxin medium by toxin-free medium after various times of incubation would provide information on the time required for each of the toxin derivatives to bind to the cell surface. We compared the three most effective phalloidin conjugates, phalloidin oleate (1e), phalloidin-Tat conjugate (2c), and phalloidin polylysine (2e) (Figure 5) and found that the exposure times necessary to achieve, e.g., a 50\% growth inhibition by a given toxin concentration after $72 \mathrm{~h}$ indeed varied considerably, from $2 \mathrm{~h}$ to $24 \mathrm{~h}$. The results show that the polycationic derivative was bound much more rapidly than the lipophilic conjugate.

\section{A fluorescent residue that enhances uptake of phal- loidin into cells}

Tetramethylrhodaminyl-phalloidin (Figure 6a) has been used to visualize actin fibers in fixed cells for 30 years. Here we show that the rhodamine residue also strongly enhanced cellular uptake, making this phalloidin derivative a tool for cell biology. With an $\mathrm{IC}_{50}$ value of $11 \mu \mathrm{M}$ its toxicity is comparable to those of the most toxic phalloidin derivatives, phalloidin oleate (1e) and phalloidin-poly-(L)-lysine (2e). More importantly, rhodaminyl-phalloidin seems not to be cleaved inside the cell and, through its fluorescence, can report on the structure of its target protein, the actin filaments, albeit under toxic conditions.

Using rhodamine-labeled phalloidin, we could also study how membrane-permeable peptides are incorporated into the cell. Immediately after exposure the toxin was located on the plasma membrane of the cells as shown by fluorescence microscopy (Figure 6c), while after $6 \mathrm{~h}$ increasing amounts of the toxin were found in endocytotic vesicles. After $24 \mathrm{~h}$ most of the rhodamine-labeled toxin was still in endosomes, while some of it had found its target, as concluded from the decoration of filaments.

\section{Phalloidin causes apoptosis of cells}

Under the microscope, cells treated with membrane-permeable phalloidin derivatives appeared shrunken and developed blebs, as described for cells undergoing apoptosis. Treatment with

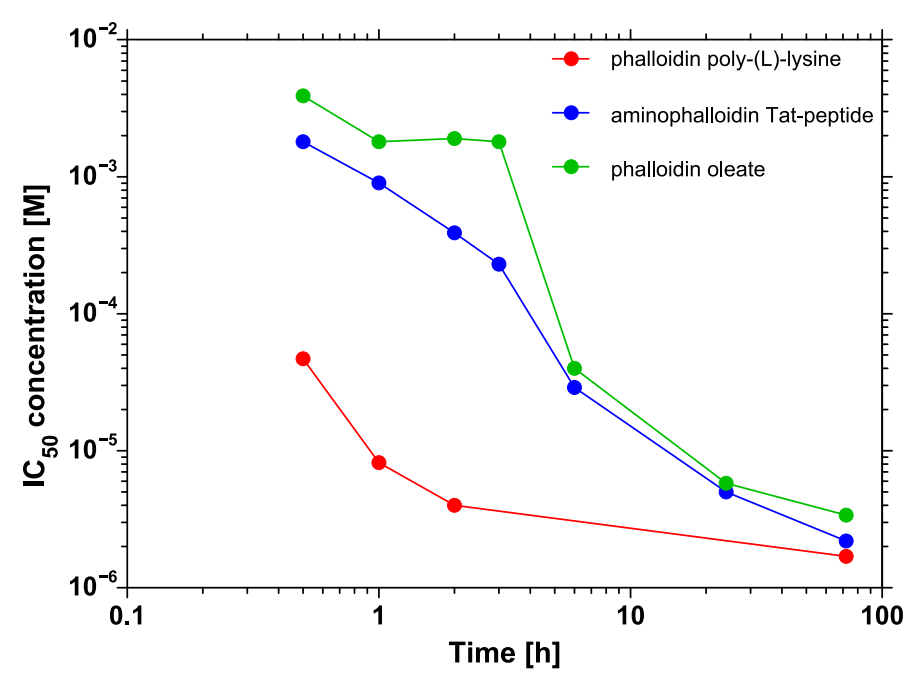

Figure 5: Time course of uptake in NIH 3T3 cells of three phalloidin derivatives as measured by the cytotoxicity after $72 \mathrm{~h}$ incubation during which the toxins were washed off after various exposure times. 


\section{a}

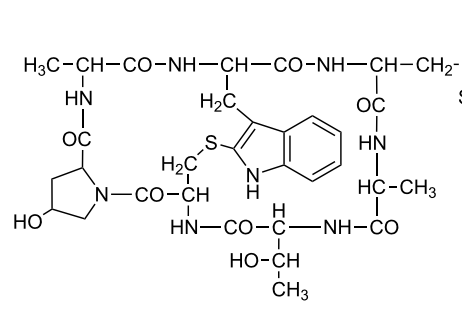

3

C

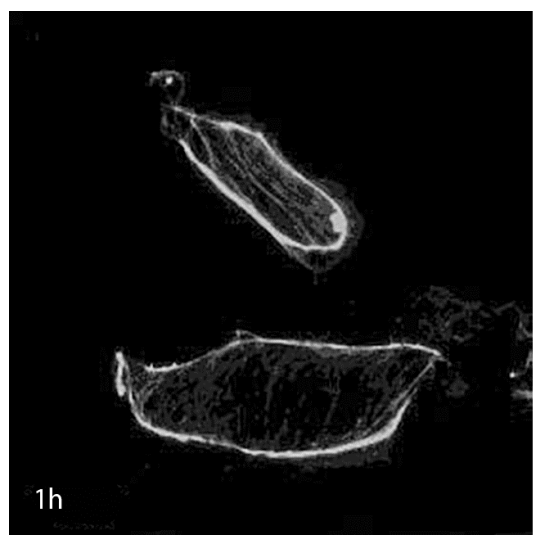

b
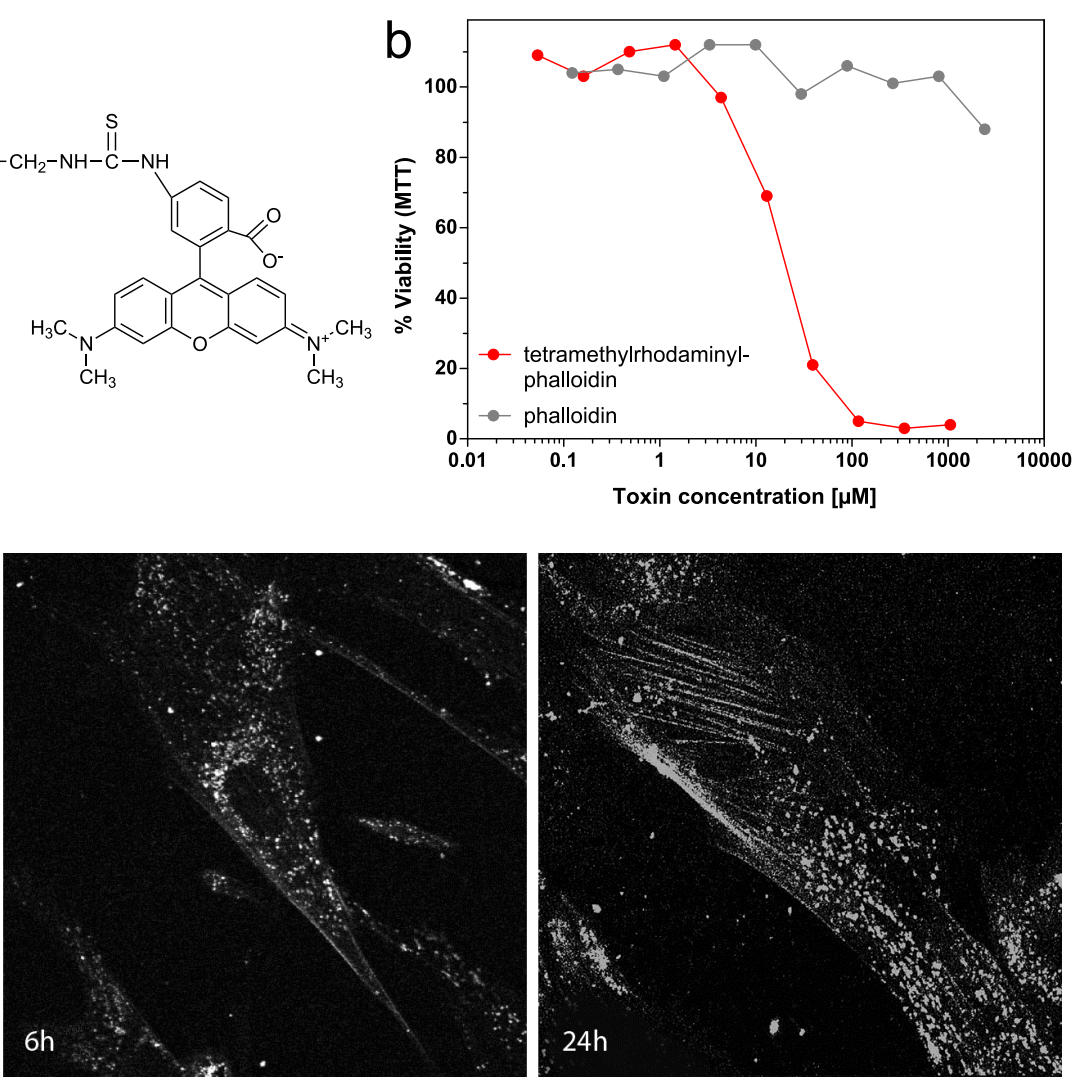

Figure 6: (a) Chemical structure of tetramethylrhodaminyl-phalloidin (3). (b) Growth inhibition of NIH 3 T3 mouse fibroblasts by tetramethylrhodaminylphalloidin (3) versus phalloidin (1) after $72 \mathrm{~h}$ incubation time. (c) Binding and uptake of tetramethylrhodaminyl-phalloidin (3) in NIH 3 T3 mouse fibroblasts after 1,6 and $24 \mathrm{~h}$, as documented by fluorescence microscopy.

annexin followed by flow cytometric analysis showed a fluorescence distribution typical for apoptosis and similar to that induced by camptothecin. Cells treated with native phalloidin were indistinguishable from controls [13].

\section{Growth inhibition by amatoxin derivatives}

Unlike the phallotoxins, the natural amatoxins are toxic in cell cultures, exhibiting $\mathrm{IC}_{50}$ values around $10^{-6} \mathrm{M}$. As amatoxins are more hydrophilic than phallotoxins, it seems unlikely that their membrane permeation capacity is larger than that of phallotoxins. The more likely explanation is that for amatoxins the threshold concentration lethal for cells is much lower than for phallotoxins (see Discussion).

Two of the internalization-mediating residues investigated in the phallotoxin series, oleic acid and polylysine, were also tested for their uptake capacity in the amatoxin series. Structure-activity studies had shown that the primary $\mathrm{OH}$ group of the dihydroxy-isoleucine moiety (Figure 7) is not involved in RNA polymerase II binding and, hence, may be used for deriva- tization with oleic acid chloride (Table 2). In order to avoid concurrent acylation of the 6'-OH of tryptophan, the phenolic $\mathrm{OH}$ was methylated before acetylation. For coupling to polylysine the natural carboxy group of aspartic acid as present in $\beta$-amanitin was used, which after activation as $N$-hydroxysuccinimide ester reacted with $\varepsilon$-amino groups in polylysine. Since

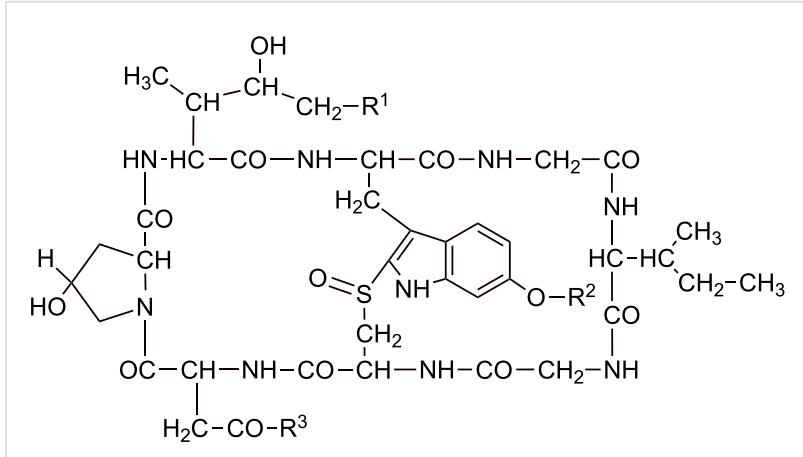

Figure 7: Chemical structure of amanitin with attachment site for conjugation to internalization-mediating moieties $\left(R^{1}, R^{3}\right)$. 
Table 2: Structures of amanitin derivatives and $I C_{50}$ concentrations of growth inhibition in mouse fibroblasts after $72 \mathrm{~h}$ incubation time (MTT cell proliferation assay).

\begin{tabular}{|c|c|c|c|c|c|}
\hline & $\mathrm{R}^{1}$ & $\mathrm{R}^{2}$ & $\mathrm{R}^{3}$ & & $\begin{array}{l}\mathrm{IC}_{50} \text { values NIH } 3 \mathrm{~T} 3 \\
\text { fibroblasts }[\mathrm{nM}]\end{array}$ \\
\hline 4 & $\mathrm{OH}$ & $\mathrm{OH}$ & $\mathrm{NH}_{2}$ & a-amanitin & 6,200 \\
\hline $4 a$ & $\mathrm{OCO}\left(\mathrm{CH}_{2}\right)_{7} \mathrm{CHCH}\left(\mathrm{CH}_{2}\right)_{7} \mathrm{CH}_{3}$ & $\mathrm{OCH}_{3}$ & $\mathrm{NH}_{2}$ & $\alpha$-amanitin oleate & 39 \\
\hline 5 & $\mathrm{OH}$ & $\mathrm{OH}$ & $\mathrm{OH}$ & $\beta$-amanitin & 1,000 \\
\hline $5 a$ & $\mathrm{OH}$ & $\mathrm{OH}$ & $\begin{array}{c}\mathrm{CO}(\text { Lys })_{m} \mathrm{OH} \\
\varepsilon \mathrm{NH}\left(\mathrm{CH}_{2}\right)-\mathrm{CH}\end{array}$ & $\begin{array}{c}\beta \text {-amanitin } \\
\text { poly-(L)-lysine }\end{array}$ & 10 \\
\hline $5 b$ & $\mathrm{OH}$ & & $\mathrm{NH}(\text { Lys })_{n} \mathrm{H}$ & $\begin{array}{c}\beta \text {-amanitin } \\
\text { poly-(D)-lysine }\end{array}$ & 18,000 \\
\hline
\end{tabular}

the polymeric carrier may be broken down inside the cell by proteases, we investigated both poly-(L)-lysine and poly-(D)lysine as carriers, in order to study whether the biological availability of the amatoxin depended on the configuration of lysine in the polymeric carrier.

Conjugation of amanitin to oleic acid increased the cytotoxicity by a factor of 150 (see Table 2). In analogy with the phallotoxins, we conclude that the oleic acid ester is hydrolysed inside the cell. $\beta$-Amanitin, when conjugated to poly-(L)-lysine, became 100-fold more toxic for mouse fibroblasts than the native toxin, showing $\mathrm{IC}_{50}$ values in the nanomolar range (Figure 8). As in the phallotoxin series, toxicity of $\beta$-amanitin conjugates depends on the cleavage of the toxin from the poly- meric carrier, as shown by the fact that $\beta$-amanitin coupled to the (L)-polymer was 1800 times more toxic than when coupled to the (D)-polymer (Table 2).

\section{Discussion}

\section{Growth inhibition as a parameter of internal- ization}

Phallotoxins as well as amatoxins find their targets inside the cell. Thus, if growth inhibition by these toxins occurs the toxins must have penetrated the cell. Moreover, the extent of the toxic lesions will mirror the amount of toxin that penetrated the cell and, hence, can be used to estimate the amount of toxin taken up. Although some of the steps involved in the uptake process became evident in this study it was not our aim to investigate

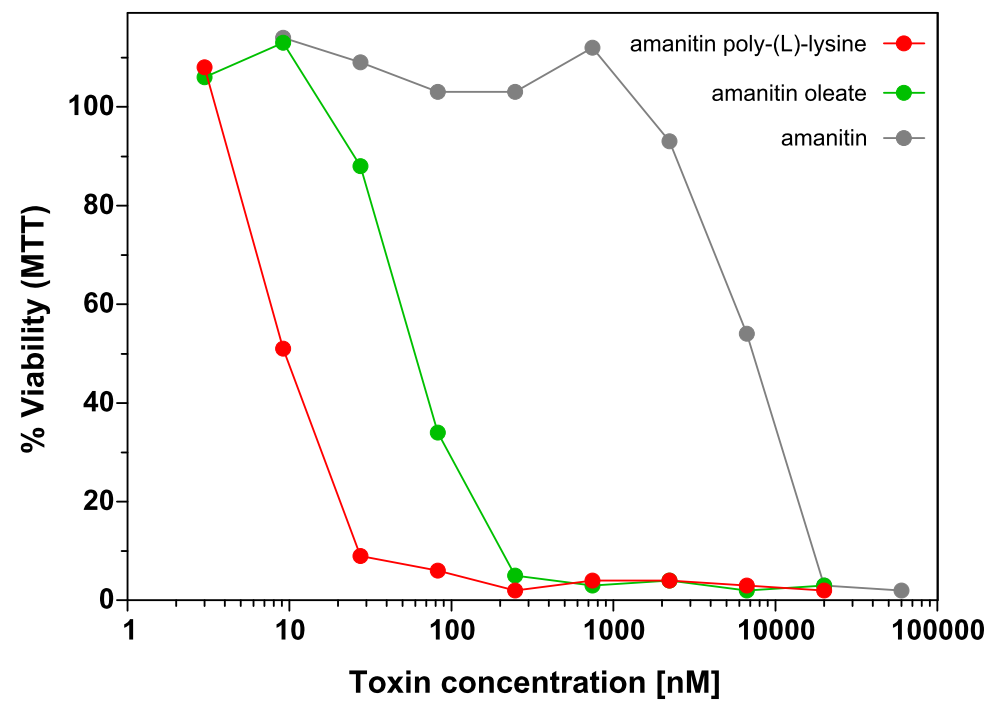

Figure 8: NIH 3T3 mouse fibroblasts were incubated with various concentrations of $\alpha$-amanitin and amanitin derivatives. Cell viability was determined after $72 \mathrm{~h}$ incubation time by MTT assay. 
details of internalization, but to gather experience with moieties that may help to overcome the plasma membrane barrier and to shift hydrophilic peptides into a cell.

\section{Previous experience with internalization-mediating moieties}

Lipid acids have been used by various researchers to enhance the uptake of peptides and proteins into cells. For example Honeycutt et al. [14] used palmitic acid to deliver a protease inhibitor into cells, and Bradley et al. [15] used docosahexanoic acid to improve the uptake of paclitaxel into tumor cells. For a review see Wong and Toth [16]. Of particular interest was the incorporation of anti-sense oligonucleotides into cells by coupling them to lipophilic ligands as reported by Boutorin et al. [17], Letsinger et al. [18], and Shea et al. [19].

Polycationic carriers such as polylysine and polyarginine represent another, and possibly even more effective technique for delivering drugs into cells. Ryser and Shen [20] reported the internalization by polylysine of methothrexate and horse radish peroxidase; Leonetti et al. [21] the internalization of oligonucleotides; and Mulders et al. [22] the internalization of adenovirus into cells. A polylysine peptoid derivative was used by Murphy et al. [23] for "gene delivery", and Emi et al. [24] used polyarginine as a carrier for gene transfer.

Protein transduction domains such as Tat-peptide, usually consisting of 10-30 amino acids, have been used to transport enzymes, drugs, liposomes and supermagnetic particles into cells [25-29]. In the meantime it has been shown that nona-arginine is many times more efficient than Tat-peptide, suggesting that the internalization effect of Tat-peptide is mainly due to its eight cationic side chains [30].

\section{Attachment to plasma membrane determines the rate of internalization}

Plasma membranes of cells in culture represent a lipophilic phase in an aqueous medium, and amphiphilic compounds brought into this system will distribute between the two phases according to their nature. This process is similar to the distribution the substance will take between $n$-octanol and water, an idea that has been suggested by Palm et al. [31].

Compounds 1a-1e represent a series of phalloidin derivatives with increasing $\log P_{\text {ow }}$ values. At the same time they represent a series of phalloidin derivatives with increasing cytotoxic activity. Since the two parameters are linearly related (Figure 3), we conclude that the amount of toxin attached to the membrane determines the extent of the toxic effects observed. Clearly, this conclusion is valid only under the condition that, as in our case, all derivatives belong to the same chemical class, esters for example, and that processing inside the cell will yield the same toxic product, here native phalloidin, set free in all cases.

Attachment to the plasma membrane can also occur by electrostatic forces and, thus, may be behind the internalization effect observed with polylysine or oligoarginine as well. Plasma membranes expose numerous negatively charged components that can attract oligo- or polycationic molecules. As already pointed out, arginine residues as in $\mathbf{2 d}$ are more effective than lysine residues in $\mathbf{2 e}$, as 120 lysine groups are required to match the internalization increase caused by eight arginine residues.

Concerning Tat-peptide, we believe that its eight cationic side chains interacting with the plasma membrane represent the more likely explanation for its internalization than other models proposed in the past.

Finally, tight attachment to the plasma membrane may also explain why the methoxy-polyethyleneglycol residue mediates internalization, since polyethyleneglycols are soluble not only in water but also in diethylether, i.e., can adopt a conformation capable of anchoring to the phospholipids in the plasma membrane. Lipophilic interaction of the aromatic part of tetramethylrhodamine with the plasma membrane is also thought to be the main cause of the internalization capacity of this fluorescent residue, beside its delocalized cationic charge on the two nitrogen atoms.

Although proved for a lipophilic phalloidin derivative only, we postulate that attachment to the plasma membrane also provides the first step in entering cells for the polycationic and the pegylated toxin derivatives presented in this study.

\section{Internalization and processing}

The uptake process following the binding step of the phalloidin derivative 3 to the plasma membrane was identified as endocytosis. As shown in Figure 6c, the fluorescent phalloidin is bound on the plasma membrane of mouse fibroblasts after $1 \mathrm{~h}$, while after $6 \mathrm{~h}$ most of the fluorescent material resides in endocytotic vesicles. This finding confirms the earlier observation [6] that TRITC-phalloidin 3 enters isolated mouse hepatocytes by endocytosis and not through a phalloidin-transporting protein, such as the OATP1B1 present on human hepatocytes. The type of endocytosis seen here remains, however, to be elucidated. Likewise, we have no data on whether lipophilic or polycationic phallotoxins enter cells in the same way as the fluorescent toxin, but this seems likely since proteolytic enzymes present in endosomal-lysosomal compartments were found to be involved in the processing, and the difference in de- 
gradation after arrival in endosomes is the most likely explanation for the difference found in the toxicities of phalloidin when bound to either poly-(L)- or to poly-(D)-lysine (2e).

There is no evidence so far about how phalloidin released from the carrier finds its way out of the endosomal-lysosomal compartments into cytoplasm, where the target, the actin filaments, is located.

\section{Conclusions}

With $\mathrm{IC}_{50}$ values of $>10 \mathrm{mM}\left(8 \mathrm{mg} / \mathrm{mL} ; M_{\mathrm{r}} 789 \mathrm{~g} / \mathrm{mol}\right)$, phalloidin has so far been of no benefit for research on living cells, unless it was microinjected. This is regrettable, since the molecular mechanism of phalloidin action, the immobilization of the microfilament system, has been investigated in great detail. Moreover, phalloidin action is comparable to that of taxol, which induces comparable immobilization of the microtubular system and has been widely employed in cell research and even in tumor therapy $[32,33]$. One difference is that taxol is a lipophilic compound, and is thus active on cells at much lower concentrations. We balanced this disadvantage by coupling phalloidin, e.g., to oleic acid, allowing studies of the molecular toxicity of phalloidin on cells in the micromolar range and encouraging its use in tumor therapy.

The internalization-mediating effect observed with phalloidin was seen also with amatoxins. Although amanitin is active on cells in the micromolar range, it may be advantageous to use it bound to oleic acid or polylysine and thus decrease the medium concentration necessary to achieve growth inhibition down to the nanomolar range. Amanitin as a drug bound to tumor monoclonal antibodies, has recently been described for the therapy of adenocarcinomas [34].

Coupling to methoxypolyethyleneglycol has been described as a method to improve the solubility of drugs, prolong their halflives in plasma, or modulate their pharmacokinetics [35]. An effect not described to our knowledge so far is that pegylation can enhance, several hundred-fold, the penetration of a hydrophilic drug into cells. Linkers with the drug should contain a disulfide bridge, as in compound (2i), to make sure that after internalization the drug is released in a defined and active form.

Likewise new, is the observation that the red fluorescent tetramethylrhodaminyl residue can facilitate internalization, e.g., of phalloidin, by a factor of $>100$. Linked by a thiourea moiety, as in compound $\mathbf{3}$, the fluorescent moiety is not cleaved inside the cell, as concluded from the observation that this phalloidin derivative still decorates filaments in the cell. This property of rhodamine-labeled phalloidin seems useful as a tool for studying the kinetics of phalloidin-induced disturbances in the actin system of a cell in correlation with, for example, the development of apoptosis in the cell.

\section{Experimental}

\section{Fatty acid esters of phalloidin}

Ten micromoles of phalloidin was dissolved in $0.1 \mathrm{~mL}$ dry pyridine and reacted with $0.3 \mu \mathrm{mol}$ of benzoyl chloride, salicyl chloride, octoyl chloride, myristoyl chloride, or oleoyl chloride for $2 \mathrm{~h}$ at $\mathrm{rt}$. Under these conditions, the reaction proceeded predominantly at the primary $\mathrm{OH}$ group of the $\gamma, \delta$-dihydroxyleucine residue in position 7 of phalloidin, with ca. $10-20 \%$ of esterification at the secondary $\mathrm{OH}$ groups. The reaction was stopped with $2 \mathrm{~mL}$ of methanol, and solvents were removed in vacuo at $60{ }^{\circ} \mathrm{C}$. Purification of the esters was achieved by preparative TLC on silica (Merck $\mathrm{HF}_{254}$, Darmstadt; Germany) in chloroform/methanol/2 $\mathrm{N}$ acetic acid (65:25:4), followed by further purification of the methanolic extract of the silica on a Sephadex-LH20 column developed with methanol. Yields of the esters were $43 \%$ for benzoyl phalloidin, $35 \%$ for salicyl phalloidin, $46 \%$ for octoyl phalloidin, $50 \%$ for myristoyl phalloidin and $44 \%$ for oleoyl phalloidin; purities were 88 to $95 \%$ by HPLC.

\section{Aminophalloidin}

Ten micromoles of toluene-4-sulfonyl chloride in $2 \mathrm{~mL}$ chloroform were added to $0.6 \mu \mathrm{mol}$ of phalloidin in $5 \mathrm{~mL}$ dry pyridine and allowed to react for $30 \mathrm{~min}$ on ice. The reaction was stopped by the addition of $50 \mathrm{~mL}$ of dry diethyl ether, and the sediment was isolated by centrifugation, washed twice with $50 \mathrm{~mL}$ diethyl ether, and dissolved in $5 \mathrm{~mL}$ methanol for separation on a Sephadex-LH20 $(60 \times 3 \mathrm{~cm})$ column developed with methanol/ $\mathrm{H}_{2} \mathrm{O}(1: 1)$. Yield of the monotosylphalloidin was $65 \%$; purity $94 \%$. The vacuum-dried monotosylphalloidin was dissolved in $40 \mathrm{~mL}$ of methanol containing $2.5 \mathrm{~N}$ ammonia and reacted for $2 \mathrm{~h}$. After evaporation in vacuo at $60{ }^{\circ} \mathrm{C}$, the aminophalloidin was purified on a Sephadex-LH20 column with methanol as eluant. Yield of aminophalloidin was $80 \%$, purity $89 \%$ by HPLC.

\section{Fatty acid amides of phalloidin}

Aminophalloidin and the fatty acid chlorides were reacted as described for the synthesis of phalloidin esters.

\section{Linear peptides linked to aminophalloidin}

Linear peptides such as Ac-Cys-Gly-Tyr-Gly-Arg-Lys-LysArg-Arg-Gln-Arg-Arg-Arg-OH (Tat peptide), and Ac-Cys-Gly$\mathrm{Arg}_{8}-\mathrm{OH}\left(\mathrm{Arg}_{8}\right)$ were synthesized on an Eppendorf Ecosyn P solid-phase synthesizer by using 9-fluorenylmethoxycarbonyl (Fmoc)-Arg(Pbf)SPHB resin (Rapp Polymere, Tübingen, Germany). For the Kaposi sequence Ac-Cys-Gly-Ala-Ala-Val- 
Ala-Leu-Leu-Pro-Ala-Val-Leu-Leu-Ala-Leu-Leu-Ala-Pro-OH an Fmoc-Pro-Trt-Tentagel resin was used. All amino acids were incorporated with the $\alpha$-amino functions protected with the Fmoc group. Side chain functions were protected as tert-butyl ethers (tyrosine), tert-butyloxycarbonyl derivatives (lysine), trityl derivatives (cysteine, glutamine), and as $(2,2,4,6,7$ pentamethyl)dihydrobenzofuran-5-sulfonyl derivative (arginine). Coupling was performed by using a 4-fold excess of each of the protected amino acids and the coupling reagent 2-(1H-benzotriazole-1-yl)-1,1,3,3-tetramethyluronium tetrafluoborate (TBTU) and 2 equiv of diisopropylethylamine (DIEA) over the resin loading. Before the coupling steps the Fmoc groups were removed from the last amino acid of the growing peptide fragment by using $25 \%$ piperidine in dimethylformamide. After cleavage of the N-terminal Fmoc group, the peptide was removed from the resin under simultaneous cleavage of the amino-side-chain protecting groups by incubation for $3 \mathrm{~h}$ in a mixture of trifluoroacetic acid (TFA) $(12 \mathrm{~mL})$, ethanedithiol $(0.6 \mathrm{~mL})$, anisole $(0.3 \mathrm{~mL})$, water $(0.3 \mathrm{~mL})$, and triisopropylsilane $(0.15 \mathrm{~mL})$. The mixture was filtered, and washed with TFA and anhydrous diethyl ether. The crude products were further purified by HPLC on a Nucleosil 100 C18 $(7 \mu \mathrm{m})$ column $(250 \times 10 \mathrm{~mm}$, Macherey \& Nagel, Düren, Germany) by using a gradient from $10-90 \% \mathrm{~B}$ in $32 \mathrm{~min}$ (solution A: $0.07 \% \mathrm{TFA} / \mathrm{H}_{2} \mathrm{O}$; solution B: $0.059 \%$ TFA in $80 \%$ acetonitrile). The elution was monitored at $214 \mathrm{~nm}$. The peptides were assayed for purity by analytical HPLC and ESIMS. The peptides were coupled to aminophalloidin through the heterobifunctional cross-linking agent SPDP (3-(2-pyridyldithio)propionic acid $N$-hydroxysuccinimide ester). Thus, the activated ester end of excess SPDP was reacted with the primary amine group in aminophalloidin to form an amide linkage. In general, $63 \mu$ mol aminophalloidin were dissolved in $3.4 \mathrm{~mL} \mathrm{H}_{2} \mathrm{O}$ and 1.7 equiv SPDP, dissolved in $900 \mu \mathrm{L}$ dimethylformamide, were added. The solution was adjusted to $\mathrm{pH} 7.5$ with $1 \mathrm{~N} \mathrm{NaOH}$; reaction time was $1 \mathrm{~h}$. Separation of the products was performed by Sephadex-LH20 column developed with methanol. The purity of PDP-aminophalloidin was $93 \%$; the yield was about $65 \%$. The 2-pyridyldithiol group at the other end of the linker was reacted with the sulfhydryl in the amino terminal Ac-Cys-Gly moiety of the linear peptides to form a disulfide group. The reaction conditions of the three linear peptides varied slightly and were as follows: $33 \mu \mathrm{mol}$ Tatpeptide, dissolved in $1.0 \mathrm{~mL}$ PBS was added to $40 \mu \mathrm{mol}$ of PDP-aminophalloidin dissolved in $0.5 \mathrm{~mL}$ methanol; $13.6 \mu \mathrm{mol}$ $\mathrm{Arg}_{8}$-peptide, dissolved in $1.5 \mathrm{~mL}$ PBS was added to $28 \mu \mathrm{mol}$ of PDP-aminophalloidin dissolved in $0.25 \mathrm{~mL}$ methanol; $12 \mu \mathrm{mol}$ Kaposi-peptide, dissolved in $0.8 \mathrm{~mL}$ PBS was added to $36 \mu \mathrm{mol}$ of PDP-aminophalloidin dissolved in $0.2 \mathrm{~mL}$ methanol. Reaction time was in all cases $16 \mathrm{~h}$ at rt. Separation was achieved on Sephadex-LH20 with $\mathrm{H}_{2} \mathrm{O}$ /methanol (4:1) as solvent. Yield for Tat-phalloidin was 52\%, for $\mathrm{Arg}_{8}$-phalloidin $43 \%$ and for Kaposi-peptide 39\%. Purity of all conjugates was $>90 \%$ as shown by HPLC (Table 1) and MALDI-TOF analysis. The HPLC analysis conditions were as follows: Column Knauer RP Nucleosil-100 C18 $(250 \times 4 \mathrm{~mm})$; mobile phase was a linear gradient of buffer $\mathrm{A}_{2} \mathrm{O}, 0.05 \%$ TFA and buffer $\mathrm{B}$ acetonitrile/ $\mathrm{H}_{2} \mathrm{O}$ (9:1), 0.05\% TFA.; flow rate, $1.2 \mathrm{~mL} / \mathrm{min}$.

\section{General}

MALDI-TOF analysis was performed in the linear, high-mass, positive-ion mode with pulsed (time-delayed) extraction on a Kratos Maldi IV instrument (Shimadzu Deutschland, Duisburg, Germany). Samples (usually in $0.1 \%$ TFA) were either applied by a sandwich technique (in which $0.7 \mu \mathrm{L}$ of matrix was dried onto the sample spot, followed by $0.7 \mu \mathrm{L}$ of sample and then another $0.7 \mu \mathrm{L}$ of matrix) or, for more concentrated samples, were simply mixed 1:10 with the matrix solution and $0.7 \mu \mathrm{L}$ of this mixture was dried onto the stainless-steel sample holder. Matrix solutions were usually $\alpha$-cyano-4-hydroxycinnamic acid [dissolved at $10 \mathrm{mg} / \mathrm{mL}$ in $50 \%$ acetonitrile, $50 \% 0.1 \%$ TFA (all $\% \mathrm{v} / \mathrm{v})]$. Spectra were calibrated by using near-external standards consisting of a mixture of fragment $1-4$ of substance $\mathrm{P}$ $([\mathrm{M}+\mathrm{H}] \mathrm{m} / \mathrm{z}$ 497.6); angiotensin II ([M $+\mathrm{H}] \mathrm{m} / z$ 1047.2); angiotensin I $([\mathrm{M}+\mathrm{H}] \mathrm{m} / \mathrm{z}$ 1297.5); fragment $1-13$ of angiotensinogen $([\mathrm{M}+\mathrm{H}] m / z$ 1646.9); and oxidized insulin $\mathrm{B}$ chain $([\mathrm{M}+\mathrm{H}] \mathrm{m} / z$ 3496.9). Absolute $m / z$ values occasionally varied up to $1 \mathrm{Da}$ depending on the individual calibration and the distance and time between the individual measurements; for these samples, spectra were recalibrated by using known $\mathrm{m} / \mathrm{z}$ values of the largest peak(s). Spectra were collected and analyzed by using standard Kratos software (Sun OS, Release 5.4, OpenWindows Ver. 3.4, Kratos Kompact Software Ver. 5.2.0) and were usually the average of 50-100 individual laser shots across the width of the sample spot. Data were smoothed and baseline-corrected, generally with a window width of 30 channels.

\section{Polymers linked to aminophalloidin}

Poly-(L)-lysine (hydrobromide; $M_{\mathrm{r}}=27500$ ), and monomethoxy-polyethyleneglycolamine $\left(M_{\mathrm{r}}=810,5200,22600\right)$ were coupled to aminophalloidin by the amine-reactive homobifunctional cross-linking reagents DSP (dithiobis(succinimidylpropionate); Lomant's reagent) with cleavable disulfide group, or DSS (disuccinimidyl suberate) containing a hydrocarbon chain instead of the disulfide group. DSP or DSS $(248 \mu \mathrm{mol})$ were dissolved in $1.0 \mathrm{~mL}$ of $N, N$-dimethylformamide and added to $63 \mu \mathrm{mol}$ dried aminophalloidin. The reaction was started with $2 \mu \mathrm{L}$ triethylamine and allowed to proceed under magnetic stirring for $16 \mathrm{~h}$ at $\mathrm{rt}$. The reaction was stopped with $10 \mathrm{~mL}$ diethyl ether and the mixture was centrifuged; after a second wash with ether, the sediment was dissolved in $5 \mathrm{~mL}$ 
methanol and separated on a Sephadex-LH20 column with methanol as solvent. Yield of DSP-, and DSS-phalloidin was about $80 \%$, purity $>90 \%$ for both.

Seven milligrams DSP-, or DSS-phalloidin were dissolved in $0.5 \mathrm{~mL} N, N$-dimethylformamide and 5 equiv of poly-(L)-lysine hydrobromide or poly-(D)-lysine hydrobromide added in $0.5 \mathrm{~mL}$ PBS. After reaction for $16 \mathrm{~h}$ at $\mathrm{rt}$, high-molecularweight products were separated by gel-filtration chromatography with Sephadex G-25 with $0.1 \% \mathrm{NaCl}$ as eluant. After lyophilisation, the amount of phalloidin coupled to the polymer was determined from the characteristic absorption of phalloidin at $300 \mathrm{~nm}(\varepsilon=10,100)$. We found that ca. 1 out of ca.10 lysine residues was spiked with aminophalloidin, independent of the molecular weight of the polymer. For modification of DSPphalloidin and DSS-phalloidin with methoxypolyethyleneglycolamine, monomethoxypolyethyleneglycol was tosylated and reacted with ammonia to yield monomethoxy-PEG with a reactive amino group: $100 \mathrm{mg}$ monomethoxy-PEG 810, 5,200 and 22,600 were dissolved in $1.0 \mathrm{~mL}$ of dry pyridine in a roundbottom flask on ice, and 5 equiv toluol-4-sulfonylchloride in $0.4 \mathrm{~mL}$ chloroform were added dropwise. After being stirred for $30 \mathrm{~min}$, the reaction was stopped with $20 \mathrm{~mL}$ of diethyl ether. Sediment was dried in a rotation evaporator and reacted with $20 \mathrm{~mL}$ of methanol/2.5 N ammonia. After $1 \mathrm{~h}$, the solvent was evaporated in vacuo and the aminomonomethoxy-PEG purified by Sephadex-LH20 chromatography. Ten milligrams DSP- or DSS-aminophalloidin were dissolved in $0.5 \mathrm{~mL} \mathrm{~N}, N$-dimethylformamide and added to 1 equiv dry aminomonomethoxy-PEG. After reaction for $16 \mathrm{~h}$ at rt, phalloidin PEG 22,600 and phalloidin PEG 5,200 were purified on a Sephadex G25 column by using $0.1 \% \mathrm{NaCl}$ as solvent, and phalloidin PEG 810 was purified on a Sephadex-LH20 column developed with methanol. The yield was $37 \%$ for phalloidin PEG 22,600, 34\% for phalloidin PEG 5,200 and 45\% for phalloidin PEG 810.

\section{Affinity to rabbit muscle actin}

Actin was prepared from rabbit muscle as described previously [36]. The binding assay was used with the following modifications: Freshly prepared G-actin solution was diluted in TrisATP buffer (2 mM of Tris; $0.2 \mathrm{mM} \mathrm{ATP;} 0.1 \mathrm{mM} \mathrm{CaCl}_{2}$; $0.02 \% \mathrm{NaN}_{3} ; \mathrm{pH} 7.8$ ) to an extinction of 0.28 at $290 \mathrm{~nm}$ (null balance at $310 \mathrm{~nm}$ ). Typically, $18 \mu \mathrm{L}$ of a $\left[{ }^{3} \mathrm{H}\right]$-demethylphalloin methanolic solution (specific activity $9 \mathrm{Ci} / \mathrm{mmol}$ ) was evaporated in a scintillation tube by a hot-air dryer, and $1.5 \mathrm{~mL}$ of G-actin solution was added. Polymerisation was initiated by addition of $12.5 \mu \mathrm{L} 0.2 \mathrm{M} \mathrm{MgCl}_{2}$. After $30 \mathrm{~min}$ incubation at room temperature the solution was filled up to ten volumes with Tris-ATP buffer and gently homogenized. Hydrophilic toxin derivatives were dissolved in potassium Tris-buffer $(100 \mathrm{mM}$ $\mathrm{KCl}, 1 \mathrm{mM}$ Tris, $\mathrm{pH}$ 7.4). The concentration was determined spectrophotometrically at $300 \mathrm{~nm}\left(\varepsilon(300 \mathrm{~nm})=10100 \mathrm{M}^{-1}\right.$ $\mathrm{cm}^{-1}$ ). Hydrophobic toxin derivatives, because of low solubility in aqueous solvents, were dissolved in methanol. Concentration was determined spectophotometrically at $300 \mathrm{~nm}$. The methanolic solution was filled up to three volumes with potassium Tris-buffer, and a dilution series established down to a concentration of $10^{-7} \mathrm{M}$. Fifty microliters of this solution was added to $450 \mu \mathrm{L}$ of the above actin solution and allowed to equilibrate for $1 \mathrm{~h}$. Samples of $180 \mu \mathrm{L}$ of this solution were transferred to Ti 42.2 centrifugation tubes (Beckman) and centrifuged at $40.000 \mathrm{rpm}$ for $50 \mathrm{~min}$ at $10{ }^{\circ} \mathrm{C}$. Twenty microliter aliquots of the supernatant were counted, and affinity values based on phalloidin $=1$ were calculated from those concentrations of phallotoxins required for a $50 \%$ substitution of the $\left[{ }^{3} \mathrm{H}\right]$-demethylphalloin.

\section{MTT proliferation assay}

Mouse fibroblasts NIH 3T3 (generous donation from Prof. Traub, MPI Ladenburg), K562, HL-60 and Jurkat cells (ATCC) maintained in RPMI 1640 medium containing $10 \%$ fetal calf serum and $0.05 \mathrm{mM} \beta$-mercaptoethanol, were cultured at $37^{\circ} \mathrm{C}$ in a humidified $95 \%$ air $/ 5 \% \mathrm{CO}_{2}$ incubator. The cytotoxicity of phallotoxins was assessed by using the 3-(4,5-dimethylthiazol2-yl)-2,5-diphenyltetrazolium bromide (MTT) assay. Exponentially growing cells were plated at a density of $2 \times 10^{4}$ cells/well in 96-well plates $24 \mathrm{~h}$ before the toxin was added in medium with up to $1 \%$ DMSO, with a volume equal to the volume of medium in the culture dish. The final concentrations of toxins in the media were between $10^{-3}$ and $10^{-9} \mathrm{M}$. At $72 \mathrm{~h}$, the medium was replaced by serum-free medium containing $25 \mu \mathrm{L}$ MTT solution ( $5 \mathrm{mg} / \mathrm{mL}$ in PBS), and the incubation was continued at $37{ }^{\circ} \mathrm{C}$ for $4 \mathrm{~h}$. Then, lysis buffer $(100 \mu \mathrm{L} 20 \%$ SDS in $50 \%$ dimethylformamide) was added to each well and incubated for another 16-20 h. Viability of cells was determined by measuring the $570 \mathrm{~nm}$ absorbance of each well using a microplate reader (Molecular Devices). $\mathrm{IC}_{50}$ values were calculated as the concentration of toxin required to reduce the absorbance to $50 \%$ of the control cultures.

\section{Microscopic studies}

Exponentially growing fibroblasts were plated at a density of $2 \times 104$ cells/well in glass-bottom dishes $24 \mathrm{~h}$ before the fluorescently labeled peptides were added. The final concentration of the peptides was $10^{-5} \mathrm{M}$. After different incubation times the cells were washed with fresh medium, and microscopic studies were performed by using a confocal laser scanning microscope TCS SP2 (Leica Microsystems, Heidelberg/Mannheim, Germany), equipped with an inverted microscope DMIRE2 and an incubation chamber (Pe-Con Erbach, Germany). Image data stacks and time-lapse studies of the live cells were obtained at $37{ }^{\circ} \mathrm{C}$ and in $5 \% \mathrm{CO}_{2}$ atmosphere with a $100 \times / 1.4$ N.A. 
oil immersion objective and CLSM software (Leica Microsystems). The data were processed with ImageJ software, optimizing images in brightness and contrast, and visualization of the fluorescing structures was performed on serial confocal optical sections.

\section{Supporting Information}

\section{Supporting Information File 1}

Structures of phalloidin derivatives and $\mathrm{IC}_{50}$ concentration values of cell growth inhibition.

[http://www.beilstein-journals.org/bjoc/content/ supplementary/1860-5397-8-233-S1.pdf]

\section{References}

1. Wieland, T. Peptides of Poisonous Amanita Mushrooms; Springer Series in Molecular and Cell Biology; Springer: Berlin, Heidelberg, Germany, 1986.

2. Roeder, R. G.; Rutter, W. J. Nature 1969, 224, 234-237. doi: $10.1038 / 224234 a 0$

3. Chambon, P.; Gissinger, F.; Kedinger, C.; Mandel, J. L.; Meilhac, M. The Cell Nucleus; Academic Press: New York, 1974; Vol. III.

4. Wehland, J.; Weber, K. Eur. J. Cell Biol. 1981, 24, 176-183.

5. Wulf, E.; Deboben, A.; Bautz, F. A.; Faulstich, H.; Wieland, T. Proc. Natl. Acad. Sci. U. S. A. 1979, 76, 4498-4502. doi:10.1073/pnas.76.9.4498

6. Faulstich, H.; Trischmann, H.; Mayer, D. Exp. Cell Res. 1983, 144, 73-82. doi:10.1016/0014-4827(83)90443-3

7. Bushnell, D. A.; Cramer, P.; Kornberg, R. D Proc. Natl. Acad. Sci. U. S. A. 2002, 99, 1218-1222. doi:10.1073/pnas.251664698

8. Fehrenbach, T.; Cui, Y.; Faulstich, H.; Keppler, D. Naunyn Schmiedebergs Arch. Pharmacol. 2003, 368, 415-420. doi:10.1007/s00210-003-0814-4

9. Meier-Abt, F.; Faulstich, H.; Hagenbuch, B. Biochim. Biophys. Acta 2004, 1664, 64-69. doi:10.1016/j.bbamem.2004.04.004

10. Letschert, K.; Faulstich, H.; Keller, D.; Keppler, D. Toxicol. Sci. 2006, 91, 140-149. doi:10.1093/toxsci/kfj141

11. Heitz, F.; Morris, M. C.; Divita, G. Br. J. Pharmacol. 2009, 157, 195-206. doi:10.1111/j.1476-5381.2009.00057.x

12. Jones, A. T.; Sayers, E. J. J. Control. Release 2012, 161, 582-591. doi:10.1016/j.jconrel.2012.04.003

13. Anderl, J. Synthesis and cytotoxicity of membrane-permeable phallotoxins, Doctoral Thesis, Heidelberg University, Germany, 2003

14. Honeycutt, L.; Wang, J.; Ekrami, H.; Shen, W.-C. Pharm. Res. 1996, 13, 1373-1377. doi:10.1023/A:1016078118033

15. Bradley, M. O.; Swindell, C. S.; Anthony, F. H.; Witman, P. A.; Devanesan, P.; Webb, N. L.; Baker, S. D.; Wolff, A. C.; Donehower, R. C. J. Control. Release 2001, 74, 233-236. doi:10.1016/S0168-3659(01)00321-2

16. Wong, A.; Toth, I. Curr. Med. Chem. 2001, 8, 1123-1136. doi:10.2174/0929867013372535

17. Boutorin, A. S.; Gus'kova, L. V.; Ivanova, E. M.; Kobetz, N. D.; Zarytova, V. F.; Ryte, A. S.; Yurchenko, L. V.; Vlassov, V. V. FEBS Lett. 1989, 254, 129-132. doi:10.1016/0014-5793(89)81023-3
18. Letsinger, R. L.; Zhang, G. R.; Sun, D. K.; Ikeuchi, T.; Sarin, P. S. Proc. Natl. Acad. Sci. U. S. A. 1989, 86, 6553-6556. doi:10.1073/pnas.86.17.6553

19. Shea, R. G.; Masters, J. C.; Bischofberger, N. Nucleic Acids Res. 1990, 18, 3777-3783. doi:10.1093/nar/18.13.3777

20. Ryser, H. J.-P.; Shen, W.-C. Proc. Natl. Acad. Sci. U. S. A. 1978, 75, 3867-3870. doi:10.1073/pnas.75.8.3867

21. Leonetti, J. P.; Degols, G.; Lebleu, B. Bioconj. Chem. 1990, 1 , 149-153. doi:10.1021/bc00002a010

22. Mulders, P.; Pang, S.; Dannull, J.; Kaboo, R.; Hinkel, A.; Michel, K.; Tso, C.-L.; Roth, M.; Belldegrun, A. Cancer Res. 1998, 58, 956-961.

23. Murphy, J. E.; Uno, T.; Hamer, J. D.; Cohen, F. E.; Dwarki, V.; Zuckermann, R. N. Proc. Natl. Acad. Sci. U. S. A. 1998, 95, 1517-1522. doi:10.1073/pnas.95.4.1517

24. Emi, N.; Kidoaki, S.; Yoshikawa, K.; Saito, H. Biochem. Biophys. Res. Commun. 1997, 231, 421-424. doi:10.1006/bbrc. 1997.6125

25. Fawell, S.; Seery, J.; Daikh, Y.; Moore, C.; Chen, L. L.; Pepinsky, B.; Barsoum, J. Proc. Natl. Acad. Sci. U. S. A. 1994, 91, 664-668. doi:10.1073/pnas.91.2.664

26. Anderson, D. C.; Nichols, E.; Manger, R.; Woodle, D.; Barry, M.; Fritzberg, A. R. Biochem. Biophys. Res. Commun. 1993, 194, 876-884. doi:10.1006/bbrc.1993.1903

27. Allinquant, B.; Hantraye, P.; Mailleux, P.; Moya, K.; Bouillot, C.; Prochiantz, A. J. Cell Biol. 1995, 128, 919-927. doi:10.1083/jcb.128.5.919

28. Rothbard, J. B.; Garlington, S.; Lin, Q.; Kirschberg, T.; Kreider, E.; McGrane, P. L.; Wender, P. A.; Khavari, P. A. Nat. Med. 2000, 6, 1253-1257. doi:10.1038/81359

29. Torchilin, V. P.; Rammohan, R.; Weissig, V.; Levchenko, T. S. Proc. Natl. Acad. Sci. U. S. A. 2001, 98, 8786-8791. doi:10.1073/pnas.151247498

30. Wender, P. A.; Mitchell, D. J.; Pattabiraman, K.; Pelkey, E. T.; Steinman, L.; Rothbard, J. B. Proc. Natl. Acad. Sci. U. S. A. 2000, 97, 13003-13008. doi:10.1073/pnas.97.24.13003

31. Palm, K.; Luthman, K.; Ungell, A.-L.; Strandlund, G.; Artursson, P. J. Pharm. Sci. 1996, 85, 32-39. doi:10.1021/js950285r

32. Schiff, P. B.; Horwitz, S. B. Proc. Natl. Acad. Sci. U. S. A. 1980, 77, 1561-1565. doi:10.1073/pnas.77.3.1561

33. Perez, E. A. Mol. Cancer Ther. 2009, 8, 2086-2095. doi:10.1158/1535-7163.MCT-09-0366

34. Moldenhauer, G.; Salnikov, A. V.; Lüttgau, S.; Herr, I.; Anderl, J.; Faulstich, H. J. Natl. Cancer Inst. 2012, 104, 622-634. doi:10.1093/jnci/djs140

35. Veronese, F. M.; Mero, A. BioDrugs 2008, 22, 315-329. doi:10.2165/00063030-200822050-00004

36. Spudich, J. A.; Watt, S. J. Biol. Chem. 1971, 246, 4866-4871. 


\section{License and Terms}

This is an Open Access article under the terms of the Creative Commons Attribution License

(http://creativecommons.org/licenses/by/2.0), which permits unrestricted use, distribution, and reproduction in any medium, provided the original work is properly cited.

The license is subject to the Beilstein Journal of Organic Chemistry terms and conditions:

(http://www.beilstein-journals.org/bjoc)

The definitive version of this article is the electronic one which can be found at:

doi:10.3762/bjoc. 8.233 